UDC $94,323.22$

Submitted: 21.06 .2017

LBC 63.3(4/8)

Accepted: 18.10 .2017

\title{
THE PROTEST ACTIONS OF SOUTH AFRICAN YOUTH IN THE CONTEXT OF THE CURRENT CRISIS OF HIGHER EDUCATION
}

\author{
Valentina V. Gribanova \\ Institute for African Studies of Russian Academy of Sciences, Moscow, Russian Federation
}

\begin{abstract}
The article is devoted to the current problem of student and youth protest actions that took place in South Africa in 2015-2017. The author shows their influence on the political life of the country. The socioeconomic and ideological reasons for the initiation of the student riots are analyzed. The connection of protests with the general crisis of higher education in South Africa is traced. The study is based on the analysis of the South African print media of recent years. The author analyzes main events and results of the protests that took place in the autumn of 2015, the aggravation of the situation in the sphere of higher education in connection with the student riots in the autumn of 2016, and the unsuccessful attempt to hold the Higher Education National Convention in March 2017. These events became the stages of the movement "Fees must fall" for the abolition of universities fees. The author evaluates the participation of modern youth and student parties and associations in the protests. It is noted that youth and student protests are used by the left and radical parties of the South African political spectrum in the struggle for influence in the country.

Key words: South African universities, free higher education, riots, youth movements, Higher Education National Convention.

Citation. Gribanova V.V. The Protest Actions of South African Youth in the Context of the Current Crisis of Higher Education. Vestnik Volgogradskogo gosudarstvennogo universiteta. Seriya 4, Istoriya. Regionovedenie. Mezhdunarodnye otnosheniya [Science Journal of Volgograd State University. History. Area Studies. International Relations], 2018, vol. 23, no. 2, pp. 177-185. (in Russian). DOI: https://doi.org/10.15688/jvolsu4.2018.2.15
\end{abstract}

УДК $94,323.22$

Дата поступления статьи: 21.06.2017

ББК 63.3(4/8)

Дата принятия статьи: 18.10.2017

\section{АКЦИИ ПРОТЕСТА МОЛОДЕЖИ ЮАР В КОНТЕКСТЕ СОВРЕМЕННОГО КРИЗИСА СИСТЕМЫ ВЫСШЕГО ОБРАЗОВАНИЯ СТРАНЫ}

\author{
Валентина Валерьевна Грибанова \\ Институт Африки РАН, г. Москва, Российская Федерация
}

\begin{abstract}
Аннотация. Статья посвящена актуальной проблеме студенческих и молодежных акций протеста, происходивших в последние два года в Южной Африке, а также их влиянию на политическую жизнь страны. Анализируются социально-экономические и идеологические предпосылки для развития студенческих волнений, их связь с общим кризисом системы высшего образования в ЮАР. Исследование базируется на анализе южноафриканской прессы последних лет. Рассмотрены основные события и результаты протестов осени 2015 г., обострение ситуации в высшем образовании в связи с акциями протеста в университетах осенью 2016 г. и неудачная попытка проведения Национального Конвента по высшему образованию в марте 2017 года. Все это стало этапами движения за отмену платы за обучение в университетах, получившего название «Fees must fall». Дана оценка участию в акциях протеста современных молодежных и студенческих партий и объединений. Отмечено, что молодежные и студенческие выступления протеста используют левые и радикальные элементы политического спектра ЮАР в борьбе за влияние в стране.
\end{abstract}


Ключевые слова: университеты Южной Африки, бесплатное высшее образование, акции протеста, молодежные движения, Национальный Конвент по высшему образованию.

Цитирование. Грибанова В. В. Акции протеста молодежи ЮАР в контексте современного кризиса системы высшего образования страны // Вестник Волгоградского государственного университета. Серия 4, История. Регионоведение. Международные отношения. - 2018. - Т. 23, № 2. - C. 177-185. - DOI: https:// doi.org/10.15688/jvolsu4.2018.2.15

Осенью 2015 г. по ЮАР прошла волна студенческих и молодежных волнений, получивших название «Fees must fall», или движение за отмену платы за обучение в университетах (университетских сборов). Движение стало развиваться в октябре в ответ на заявление о повышении платы за обучение. Протесты начались 14 октября в Витватерсрандском университете (Wits) ${ }^{1}$, который первым объявил о необходимости повышения с января 2016 г. $^{2}$ оплаты на 10,5 \% (официально инфляция в 2015 г. составила $6 \%$ ).

Повышение объяснялось как влиянием инфляции на расходы университета, так и плановым увеличением жалования преподавателям, которое обязательно происходит раз в три года на 7 \%. Кроме того, падение курса ранда к доллару в реальности на $22 \%$ привело к серьезному возрастанию расходов на покупку книг, журналов, электронных ресурсов, исследовательского оборудования.

После начала протестов часть студентов и персонала Wits оставалась в университете до 17 октября. В этот день было объявлено о приостановлении решения о повышении платы за обучение и отказе от дисциплинарных санкций в отношении участников движения. После 19 октября подобные волнения охватили Кейптаунский университет и университет Родса. А 20 октября протестующими оказались заняты кампусы Технологического университета Капского полуострова и университета ФортХейра. Меморандум с жалобами на руководство выпустили студенты Стелленбошского университета, а протестующие из Wits отвергли компромиссное предложение руководства о повышении оплаты всего на $6 \%$.

Ключевым событием стал проведенный 21 октября 5-тысячный марш к зданию ЮжноАфриканского Парламента в Кейптауне (в основном в нем участвовали студенты Кейптаунского университета и Технологического университета Капского полуострова). Впервые против протестующих были применены спец- средства: светошумовые гранаты, слезоточивый газ, резиновые дубинки и пули, несмотря на то что демонстрация носила подчеркнуто мирный характер. Многих арестовали. Эти события нашли бурное отражение в прессе [9; $11 ; 12 ; 16 ; 18]$.

Протесты развернулись с новой силой. Волнения прошли также в Стелленбошском университете и университете Нельсона Манделы в Порт-Элизабете, где были разгромлены учебные помещения. 22 октября в результате волнений пострадали офисы службы безопасности университета Форт-Хейр. В этот же день начались волнения в университете Йоханнесбурга ${ }^{3}$, где произошли столкновения с полицией. Но главное событие 22 октября марш студентов и молодежи к штаб-квартире АНК в Йоханнесбурге. Здесь студенты передали свой меморандум Генеральному секретарю правящей партии Гведе Манташе.

23 октября президент Джейкоб Зума объявил о том, что в 2016 г. повышения платы за обучение не будет. Протестующие, тем не менее, были расстроены тем, что президент не вышел к ним, чтобы лично объявить о своем решении. Ряд демонстрантов опять попытались штурмовать здание, чтобы поговорить с президентом. Полиция применила резиновые пули [11].

После 23 октября движение пошло на спад. Но чтобы понять значение этих событий и их влияние на дальнейшую политическую жизнь Южной Африки, рассмотрим глубже требования, возникшие в ходе протестных акций, истоки этого движения, результаты и возможные последствия.

Как только начались акции в Wits, помимо основного требования - не повышать плату за обучение - возникли более общие: увеличение зарплаты для малооплачиваемой части работников университетов (уборщики, охрана); улучшение условий их работы (недовольство рабочими контрактами); изменение положения бедных студентов и финансовой 
политики правительства в отношении университетов; решение проблем социального, экономического и расового неравенства.

Все эти требования, безусловно, имеют под собой основание. Южная Африка в 20152016 гг. направила на высшее образование менее 1 \% ВВП (точнее 0,75\%). Это меньше, чем среднемировые или даже среднеафриканские $(0,78 \%)$ расходы ${ }^{4}$. Бюджет высшего образования в 2015-2016 гг. составил 30 млрд рандов. Это тем более тревожный сигнал, что еще на год раньше на сектор высшего и профессионального образования было потрачено 76,3 млрд рандов, что составило $2 \%$ ВВП, а непосредственно университетам было перечислено из них 52,9 млрд рандов. Но еще раньше, в 2000-2013 гг., государственные гранты на университеты уже были существенно снижены. Если на рубеже тысячелетий они обеспечивали $50 \%$ расходов вузов, то к 2013 г. только 40 \%. С этим связана растущая зависимость работы университетов от оплаты студентами обучения, пожертвований и других негосударственных источников дохода. За этот же период поддержка правительством студентов резко возросла: с 2000 по 2013 г. доля государственной помощи в оплате студентами образования выросла с 2 до $11 \%$. Но при этом число студентов за этот период увеличилось на 80 \%: с 560 тысяч до 980 тысяч. Что нивелировало расходы на поддержку конкретного учащегося [6].

Правительство поощряет расширение числа студентов, не увеличивая, а наоборот, сокращая финансовую поддержку университетов. Все больший объем финансов идет на субсидирование студентам платы за обучение, а фонды на кадровые и инфраструктурные затраты сокращаются. Но увеличение количества студентов требует и увеличения аудиторий, других объектов инфраструктуры, повышения фонда заработной платы преподавателям. Это вынуждает университеты повышать плату за обучение, но из-за увеличения числа студентов государство не может реально компенсировать затраты каждому из них.

Кроме того, на ситуацию в высшем образовании и возможность обучения для всех желающих напрямую влияет экономическое и социальное неравенство, о котором ярко говорят следующие факты. Согласно официаль- ным данным статистического управления ЮАР не имеют работы около 30 \% трудоспособного населения, а процент безработных среди молодежи еще выше - до $50.47 \%$ работающих получают зарплату ниже прожиточного минимума в 3500 рандов. Один процент самых богатых южноафриканцев владеет $42 \%$ богатств страны [4].

$10 \%$ наемных работников получают 90 \% заработной платы, в то время как оставшиеся 90 \% - $10 \%$ зарплаты. На 1 \% высокооплачиваемых работников приходится почти в 400 раз больше доходов, чем на $10 \%$ самых низкооплачиваемых. Неравенство, измеряемое коэффициентом Джинни (по шкале 0 - абсолютное равенство, 1 - абсолютное неравенство), в ЮАР составляет 0,66. Даже люди, имеющие работу, в большинстве своем не могут позволить себе многие потребности. Зачастую на одного работающего приходится 3 и более иждивенцев, которых он должен содержать. Чтобы жить выше черты бедности, необходимо зарабатывать более 4000 рандов на семью из четырех человек. Более 60 \% черных южноафриканцев получают меньшие доходы [5].

Для многих семей (хотя государственное финансирование университетов и стипендии существуют) плата за обучение в университете в 40000 рандов в год (а оплата может доходить и до 60000 рандов в год) делает высшее образование недоступным. Надо учесть, что указанные суммы еще практически удваиваются, если учесть расходы на проживание, проезд и т. д. Даже семья, имеющая доход в 1 млн рандов в год (а это в 20 раз больше, чем прожиточный минимум: 4000 в месяц, 50000 в год), после уплаты налогов (400 000 рандов) должна отдать $20 \%$ своего бюджета на обучение 1 студента. Менее $1 \%$ населения могут себе это позволить [8].

Существует и другой повод для недовольства: белые преподаватели составляют 53 \% преподавательского коллектива университетов ${ }^{5}$. Что касается студентов, то в подавляющем большинстве университетов количество черных учащихся приближается к $80 \%$, а в некоторых и к $100 \%$. Лишь в трех вузах количество белых и черных студентов приблизительно равное (Северо-Западный университет, университет Претории, университет 
Родса). Но, хотя в 2013 г. 44 \% выпускников и 50 \% получивших степень $\mathrm{PhD}$ были черные, они почти полностью отсутствуют в таких областях обучения, как математика и естественные науки. Африканцы выбирают в основном гуманитарные и социальные науки, а также бизнес и менеджмент [1, с. 182-183].

Сохраняются жалобы на недостаточную африканизацию учебных программ, их европейский стиль и содержание. Наиболее радикальная часть протестующих призывает и к «деколонизации образования». Утверждается, что поскольку высшее образование формирует в первую очередь мировоззрение человека, существует опасность того, что при нынешнем положении вещей европоцентристский взгляд на мир, который маргинализует, по мнению радикалов, африканское общество, будет преобладать [5].

Протесты осени 2015 г. значительно повлияли на ситуацию в стране в целом и в высшем образовании в частности. Начавшийся в январе 2016 г. учебный семестр не принес желаемого спокойствия. B Wits, где 14 октября 2015 г. начались волнения, в январе 2016 г. была сорвана регистрация новых студентов. Организованные группы студентов университета - Совет студенческих представителей Wits (CСП), Альянс прогрессивной молодежи (AПМ) и группа «Fees must fall» Wits - предъявили список требований. Основными стали: ликвидация финансовой задолженности, препятствующей многим студентам завершить обучение, гарантия возвращения всех обучавшихся, выработка «дорожной карты» на пути к бесплатному образованию и выполнение соглашений 2015 г. между администрацией и работниками.

Университет предоставил студентам рассрочку до конца марта по выплате регистрационных взносов, но ССП настаивал на том, чтобы все студенты, даже те, кто не сможет заплатить, не были отстранены от обучения. Администрация университета признала право студентов на протест, на требование бесплатного образования для бедных студентов. Но также заявила о том, что университет не может допустить подрыва своей финансовой базы. В феврале 2016 г. активные протестные акции прошли в Кейптаунском и Северо-Западном университетах, университете Свобод- ного Государства, Витватерсрандском университете, университете Претории, университете Квазулу-Натал. Везде была сорвана регистрация в начале учебного года [13].

Среди истоков движения «Fees must fall» выделяется другое протестное движение «Rhodes must fall», начавшееся в Кейптаунском университете 9 марта 2015 года. Вместе с требованием удаления с территории университета статуи Сесиля Родса (автор Марион Уолгейт, 1934 г.) начались акции протеста. Компания получила широкое освещение в прессе. Движение «Rhodes must fall» позиционирует себя как «коллективное движение студентов и сотрудников для действий против расизма в Кейптаунском университете» [7].

Отголоски движения «Rhodes must fall» постоянно ощущаются в движении «Fees must fall». Это выражается и в похожести названий, одно явно пошло от другого, и в том, что инициаторы первого принимали активное участие в движении «Fees must fall», в частности, в Кейптаунском университете в октябре 2015 г. и феврале 2016 г., и в том, что многие требования, содержащие антирасистскую риторику, в обоих движениях перекликаются.

При том, что требования студентов носили законный характер, есть признаки того, что студенчество используют для дестабилизации положения в стране. Наблюдается четкая координация действий между разными университетами, применяются хорошо отработанные технологии разжигания массовых протестов, в том числе и через социальные сети. К студенческим акциям немедленно примкнули радикальные элементы, совершавшие поджоги зданий и провоцировавшие столкновения с полицией [2].

Еще одно движение - «Open Stellenbosh», начавшееся в середине апреля 2015 г. в Стелленбошском университете, также находится в русле студенческих протестов последнего времени и связано с движением «Fees must fall». В акции студентов и преподавателей Стелленбошского университета главный упор (помимо антирасистской и антиколониальной риторики) сделан на снижении значения языка африкаанс в обучении. Организация протеста была построена по образцу движения «Rhodes must fall». Одним из итогов движения стало то, что с 12 ноября 2015 г. ректорат 
Стелленбошского университета рекомендовал новую языковую политику в соответствии с требованиями протестующих, а именно, провозглашение английского как общепринятого языка обучения [10].

И это при том, что в целом по стране отмечается с конца 1990-х гг. рост интереса помимо английского к языку африкаанс. Причины такого роста популярности африкаанс достаточно ясны: он расценивается как один из местных языков, являясь родным не только для большой части белого населения, но также и для цветных. Он остается действительно языком межнационального общения для разных групп африканцев. На нем могут, например, объясниться представители бушменов и зулу. Примечателен тот факт, что на языке африкаанс выходит печатное издание (журнал для всей семьи) с самым крупным в стране тиражом «Huisgenoot». Африкаанс и официально находится на 3-м месте в стране по распространенности (после зулу и коса).

Реакция правительства и общества на молодежные движения свидетельствует об их широком размахе и важности в политической жизни. Помимо отмены повышения платы за обучение в 2016 г. правительство сделало ряд серьезных уступок и заявлений. 8 января 2016 г. в послании АНК президент Джейкоб Зума отметил усилия государства по улучшению доступа к высшему образованию и влияние на это студенческих протестов. Министр высшего и профессионального образования Блейд Нзиманде заявил, что в 2016 г. возможность получить послешкольное образование будет предоставлена полумиллиону человек в университетах, технических и профессиональных училищах, педагогических колледжах, кроме того, правительство выделило дополнительно 6,9 млрд рандов для финансирования университетов, а ранее уже было предоставлено 10 млрд рандов через специальный фонд NSFAS (Национальная система финансовой помощи студентам). Студенты, годовой доход семьи которых меньше 122000 рандов, получили право на помощь через этот фонд [13].

Отношение к событиям у либерально настроенной части общества ярко характеризуют слова профессора социологии из Витватерсрандского университета о том, что требования студентов поддерживают многие преподаватели, которые хотят воспитывать нацию, а не учить тех, кто способен платить за себя. Тем не менее протесты в университетах подвергаются критике в обществе в целом за все более насильственный характер. Выражается обеспокоенность тем, что количественное увеличение числа студентов не приведет к качественному улучшению знаний. Многие говорят о том, что должна быть система кредитов, которые можно будет вернуть после окончания учебного заведения и устройства на работу, как это делается в странах Европы и США. Существует дискуссия и о развитии дистанционного, заочного образования для решения проблемы. Предлагается взимать специальный налог на выпускников, когда их доход превысит определенную сумму, или финансировать всех абитуриентов через NSFAS, но только в течение первого года обучения, а затем провести жесткий отбор и переложить финансирование на частный сектор.

Новая волна протестов в рамках движения «Fees must fall» началась, как и следовало ожидать, накануне нового учебного года, то есть почти ровно год спустя. Обострение последовало вслед за заявлением министра высшего и профессионального образования ЮАР Блейда Нзиманде, которое он сделал 19 сентября 2016 года. Министр подчеркнул, что государство возьмет на себя повышение оплаты для студентов из бедных и средних слоев населения, но богатые должны будут платить за себя сами. В практическом плане это должно выглядеть так: министерство рекомендует советам университетов увеличение платы за обучение в 2017 г. не более чем на 8 \% (размер увеличения оплаты вузы должны определить сами). Требуемая сумма на каждого студента из семьи, получающей доход менее 600000 рандов в год, будет направляться государством в специальный фонд NSFAS, на что выделяется 2,5 млрд рандов (это меньше, чем было потрачено на компенсацию сохранения платы за обучение на уровне 2015 г. в 2016 г.). Это коснется от 70 до $80 \%$ учащихся вузов-бакалавров по всей стране. Кроме того, финансированием будут охвачены не только студенты университетов, но и учащиеся колледжей профессионального и технического образования, для чего должны быть до 
конца года разработаны соответствующие административные механизмы.

По поводу недовольства этим решением правительства значительной части студентов министр отметил, что те, кто в современных условиях выступает за отмену увеличения платы за обучение для всех студентов, просто защищает богатых. «Мы не можем уничтожить наши университеты во имя сохранения оплаты обучения на прежнем уровне для всех, в том числе и для богатых», - сказал Нзиманде. Он призвал студентов осознать тяжелое положение в стране, ограниченные ресурсы правительства и позволить увеличить сборы в 2017 г. с тех, кто может платить. Расходы на высшее образование растут вместе с инфляцией, и если это не учитывать, то будет страдать качество. Вместе с тем министр отметил, что он не обладает информацией, откуда и как будут поступать средства для финансирования фонда NSFAS ${ }^{6}$. Пресс-секретарь министерства финансов не смог прокомментировать этот аспект заявления Нзиманде, но сам министр образования выразил надежду, что министр финансов изложит его в своем октябрьском выступлении, касающемся бюджета на 2017 год [17].

Блейд Нзиманде сделал свое заявление после решения Национального исполнительного комитета АНК не повышать плату за обучение до тех пор, пока будет продолжаться дискуссия о будущем финансировании высшего образования. Кроме того, и Совет по высшему образованию рекомендовал Нзиманде ограничить повышение 8 \%, которые привязаны к инфляции. Также надо учесть, что для подавляющего большинства студентов правительство компенсирует затраты в 2017 г., на что правительство планирует потратить 2,5 млрд рандов. Кроме того, при президенте Зуме в 2016 г. создана комиссия по вопросам высшего образования, которая рассматривает возможность введения бесплатного обучения в вузах.

Тем не менее протесты во многих вузах не останавливаются. Лидер Совета студенческих представителей (ССП) Wits заявил, что они устали от разговоров и не хотят каждый год бороться за мораторий, а требуют структурного решения кризиса в высшем образовании. Витватерсрандский университет опять, как и осенью 2015 г., стал центром начинающихся протестов. Еще до заявления министра высшего и профессионального образования студенты Wits собрались на массовый митинг, организованный ССП вместе с ассоциированным с АНК Альянсом прогрессивной молодежи, в «Доме Соломона Махлангу» (главное административное здание университета). После заявления Нзиманде президент ССП объявил, что они отвергают любое повышение и продолжают бороться за бесплатное образование для всех. После чего было заявлено о бойкоте работы университета. Студенты разошлись по территории вуза, устраивая митинги и нарушая учебный процесс, но подчеркивая исключительно мирный характер протестов. Охрана вуза заблокировала «Дом Соломона Махлангу», а студенты продолжали, разбившись на маленькие группы, блокировать въезды и выезды в кампус, и мешали проведению занятий. «Университет не позволил нам вновь войти в “Дом Соломона Махлангу”, где мы хотели обсудить заявление министра. Если университет не откроет Дом, то мы не дадим работать университету», - сказал президент ССП [17].

В университетах Претории, Свободного Государства, Квазулу-Натала, а также Стелленбошском и Кейптаунском заявление министра также было встречено со скептицизмом. Но серьезных волнений и срыва работы не наблюдалось.

В марте 2017 г. произошло еще одно важное событие в развитии движения за реформирование системы высшего образования созыв Национального Конвента по высшему образованию, который должен был объединить студенческие организации, правительство и общество. Организаторами Конвента выступил Национальный кризисный Форум по высшему образованию, члены которого за последний год посетили все 9 провинций ЮАР и провели множество встреч с самыми разнообразными заинтересованными силами. Как отмечает деятельный участник Форума и генеральный секретарь совета церквей Южной Африки епископ М. Мпумлвана, некоторые встречи были очень напряженными, но всегда удавалось найти консенсус в отношении дальнейших действий. Конвент должен был стать частью работы Форума [14]. 
В работе Конвента, собравшегося 18 марта в Мидранде, приняли участие лидеры студенческого движения со всей страны, а также члены правительства, в частности министр высшего и профессионального образования Блейд Нзиманде и представитель государственного обвинения. Последний был включен из-за того, что многие студенты, участвовавшие в акциях 2015-2016 гг., были привлечены к уголовной ответственности. В первый же день в работе Конвента произошел сбой, и он прекратил свое заседание уже через несколько часов после начала.

Заседание открыл судья и бывший заместитель председателя Верховного Суда Д. Мосенеке, речь которого несколько раз была прервана выкриками с мест. В адрес участников - представителей Молодежной группы организации Африфорум ${ }^{7}$ прозвучали угрозы, многие из присутствующих не желали участия этой оппозиционно настроенной группы в работе Конвента. Затем было прервано выступление проректора Витватерсрандского университета Адама Хабиба, который заменил заявленного в программе, но срочно уехавшего ректора Университета Южной Африки Ахмеда Баву. Не дали начать выступление и министру Блейду Нзиманде, после отъезда которого в зале заседаний между представителями Студенческой команды «Борцов за экономическую свободу» ${ }^{8}$ и ориентированного на АНК Молодежного прогрессивного Альянса начались столкновения. Хотя работа Конвента должна была продолжаться еще два дня, из-за возможных беспорядков его закрыли.

Проректор Wits Адам Хабиб возложил всю ответственность за срыв работы Конвента на представителей «Борцов за экономическую свободу» Джулиуса Малемы. В ответ Генеральный секретарь этой партии Фиваба Мадокве заявила, что в целом ее представители были настроены конструктивно. «Мы пришли сюда не для того, чтобы сражаться, если бы мы хотели сорвать эту конференции, она бы даже не началась. Мы хотели поговорить. Но на своих условиях» [15].

Но главный вывод, который был сделан из этого события: подавляющее большинство студентов борется за одни и те же цели, но протестующие расколоты политическими партиями, их борьбой за власть и влияние. «Это была возможность провести историческое событие и уйти с важными решениями. Вместо этого, конференция была захвачена лицами, стоящими на позициях, противоположных соглашениям, с которыми мы пришли сюда» - сказал студенческий лидер из Молодежной коммунистической Лиги Пресиус Банда [15].

Таким образом, продолжающиеся на протяжении 2015-2017 гг. студенческие и молодежные акции протеста в ЮАР - значительное и имеющее важные последствия событие политической жизни страны. Обусловленные как экономическими и социальными проблемами, так и структурным кризисом в высшем образовании, они, скорее всего, будут иметь продолжение, несмотря на значительные усилия правительства погасить этот очаг недовольства. Требование молодежи и сочувствующей им части общества переросли рамки борьбы за отмену повышения платы за обучение и вышли на уровень требования бесплатного высшего образования. Более того, аналитики отмечают, что студенческие волнения в ЮАР - лишь звено в цепи действий, направленных на смену режима и свержение президента страны $[2 ; 3]$. В целом движение «Fees must fall» пытаются использовать левые и радикальные элементы политического спектра Южной Африки, выдвигая в ходе протестов лозунги борьбы за социальное, политическое, расовое равенство, деколонизацию образования, против неолиберального курса правительства в финансовой cфepe.

\section{ПРИМЕЧАНИЯ}

${ }^{1}$ После реформы 2002-2007 гг. это один из 11 вузов, ориентированных на классические университетские программы.

${ }^{2}$ Начало учебного года в ЮАР в январе.

${ }^{3}$ В 2005 г. на его базе были объединены Университет Ранд Африкаанс, техникон Витватерсранда и университет «Виста», созданный в 1982 г. в рамках программы по расширению доступа африканцев к высшему образованию.

${ }^{4}$ Для сравнения: в Сенегале и Гане расходы на высшее образование составили в этот период $1,4 \%$.

5 По данным 2012 г., белых в целом 8 \% по стране. 
${ }^{6}$ Еще в августе представитель министерства финансов заявил, что у государства нет денег на покрытие увеличения расходов на образование в университетах в 2017 г., как это было сделано в 2016 году.

7 Организация основана в 2006 г. для борьбы за гражданские права. Основное внимание уделяется, в частности, таким вопросам, как гражданское строительство, безопасность и охрана, общественные дела, местное самоуправление, экономика, образование, а также сохранению языка, культуры и наследия в Южной Африке. Участники главным образом белое население ЮАР.

8 «Борцы за экономическую свободу» оппозиционная партия в ЮАР («оппозиция слева»). Организована в 2013 г. радикальным политиком Джулиусом Малемой, известным своими выступлениями против правящей партии АНК и президента Дж. Зумы. В 2012 г. он был исключен из АНК за разжигание расовой ненависти. Основное требование программы партии: очищение экономики ЮАР от засилья белых олигархов и национализация крупных предприятий. По результатам выборов 2014 г. партия вошла в парламент, получив 25 мест.

\section{СПИСОК ЛИТЕРАТУРЫ}

1. Грибанова, В. В. Южно-Африканская Республика / В. В. Грибанова // Образование в Африке. - М. : Изд-во ИАфр РАН, 2013. - С. 156-184.

2. Мезяев, А. Попытки смены режима в ЮАР приобретают все более настойчивый характер / А. Мезяев. - Электрон. текстовые дан. - Режим доступа: http://www.fondsk.ru/news/2016/06/26/ popytki-smeny-rezhima-v-juar-priobretajut-vse-boleenastojchivyj-harakter-41091.html (дата обращения: 14.06.2017). - Загл. с экрана.

3. Мезяев, А. Попытки сместить президента ЮАР Джейкоба Зуму не прекращаются / А. Мезяев. - Электрон. текстовые дан. - Режим доступа: http://www.fondsk.ru/view/2016/11/13/popytkismestit-presidenta-juar-dzhejkoba-zumu-neprekraschajutsja-43036.html (дата обращения: 14.06.2017). - Загл. с экрана.

4. Мезяев, А. Южная Африка: профсоюзы и власть / А. Мезяев. - Электрон. текстовые дан. Режим доступа: http://www.fondsk.ru/news/2017/06/ 07/uzhnaya-africa-profsojuzy-i-vlast-44117.html (дата обращения: 14.06.2017). - Загл. с экрана.

5. Baloyi, B. South Africa's 'fees must fall' protests are about more then tuition coasts / B. Baloyi, G. Isaacs. - Electronic text data. - Mode of access: http://edition.cnn.com/2015/10/27/Africa/fees-mustfall-student-protest-south-Africa-explainer (date of access: 01.06.2017). - Title from screen.
6. Chipkin I. \#FeesMust fall: Separarating Treasury's truth from 'ultra-left' fiction. - Electronic text data. - Mode of access: http//dailymaverick.co.za/ opinionista/2016-10-16-feesmustfall-separating (date of access: 01.06.2017). - Title from screen.

7. Hall, M. The symbolic statue dividing a South Afrcan university / M. Hall. - Electronic text data. Mode of access: http://www.bbc.com/news/business31945680 (date of access: 01.06.2017). - Title from screen.

8. Hanly, P. Fees must fall / P. Hanly. - Electronic text data. - Mode of access: http://www.news24.com/ Mynews24/fees-must-fall-20151022 (date of access: 01.06.2017). - Title from screen.

9. Koyana, X. Protests continue at CPUT and Fort Hare, tensions flare / X. Koyana, M. Kekana. Electronic text data. - Mode of access: http:// ewn.co.za/2015/10/20/tensions-flare-at-CPUT-andFort-Hare-fee-protest (date of access: 15.06.2017). Title from screen.

10. Language Policy (2016-2017). - Electronic text data. - Mode of access: http://www.sun.ac.za/english/ about-us/language (date of access: 15.06.2017). - Title from screen.

11. Lazar, S. «Fees must fall»: student uprising for justice sweeps South Africa / S. Lazar. - Electronic text data. - Mode of access: http://commondreams.org/ news/2015/10/22/fees-must-fall-student-uprisingjustice-sweeps-south-africa (date of access: 14.06.2017). - Title from screen.

12. Merten, M. Riot police vs student power / M. Merten. - Electronic text data. - Mode of access: http://www.iol.co.za/news/crime-courts/riot-police-vsstudent-power-1933836 (date of access: 14.06.2017). Title from screen.

13. Nicolson, G. Fess must fall: Reloaded / G. Nicolson. - Electronic text data. - Mode of access: http://dailymaverick.co.za/article/2016-01-12-feesmust-fall-reloaded (date of access: 01.06.2017). - Title from screen.

14. Nicolson, G. \#feesMustFall: Convention brawling highlights / G. Nicolson. - Electronic text data. - Mode of access: http://dailymaverick.co.za/ article/2017-03-20-fees-must-fall (date of access: 01.06.2017). - Title from screen.

15. Rensburg, A. J. van. Disappointment after chaotic education convention cancelled / A. J. van Rensburg. - Electronic text data. - Mode of access: http://www.news24.com/South Africa/News/ disappointment-after-chaotic-education-conventioncancelled-20170318 (date of access: 14.06.2017). - Title from screen.

16. South African Students continue fees protest. Electronic text data. - Mode of access: http://bbc.com/ news/world-africa-34636419 (date of access: 14.06.2017).Title from screen. 
B.В. Грибанова. Акции протеста молодежи ЮАР в контексте кризиса системы высшего образования

17. Student are not impressed by Blade's fee Adjustment Announcement. - Electronic text data. Mode of access: http://www.thedailyvox.co.za/studantacross-country-responded-blades-fee-annoncement (date of access: 01.06.2017). - Title from screen.

18. Verasamy, D. What you need to know about \#FeesMustFall / D. Verasamy. - Electronic text data. Mode of access: http://mg.co.za/article/2015-10-19four-things-you-need-to-known-about-feesmustfall (date of access: 01.06.2017). - Title from screen.

\section{REFERENCES}

1. Gribanova V.V. Yuzhno-Afrikanskaya Respublika [Republic of South Africa]. Obrazovanie $v$ Afrike [Education in Africa]. Moscow, Inst. for African Stud., 2013, pp. 156-184.

2. Mezyayev A. Popytki smeny rezhima v YUAR priobretayut vse bolee nastoychivyy kharakter [Attempts to Change the Regime in South Africa Are Becoming More Persistent]. URL: http:// www.fondsk.ru/news/2016/06/26/popytki-smenyrezhima-v-juar-priobretajut-vse-bolee-nastojchivyjharakter-41091.html.

3. Mezyaev A. Popytki smestit prezidenta YUAR Dzheykoba Zumu ne prekrashchayutsya [Attempts to Displace President of South Africa, Jacob Zuma, Are Not Stopped]. URL: http:// www.fondsk.ru/view/2016/11/13/popytki-smestitpresiden t a - juar-d zhejk oba-zu mu - neprekraschajutsja-43036.html.

4. Mezyayev A. Yuzhnaya Afrika: profsoyuzy $i$ vlast [South Africa: Trade Unions and Power]. URL: http://www.fondsk.ru/news/2017/06/07/uzhnaya-africaprofsojuzy-i-vlast-44117.html.

5. Baloyi B., Isaacs G. South Africa's 'fees must fall' protests are about more then tuition coasts. URL: http:// edition.cnn.com/2015/10/27/Africa/fees-must-fall-studentprotest-south-Africa-explainer.

6. Chipkin I. FeesMust fall: Separarating Treasury's truth from 'ultra-left' fiction. URL: http// dailymaverick.co.za/opinionista/2016-10-16feesmustfall-separating.

7. Hall M. The symbolic statue dividing a South Afrcan university. URL: http://www.bbc.com/news/ business-31945680.

8. Hanly P. Fees must fall. URL: http://www. news24.com/Mynews24/fees-must-fall-20151022.

9. Koyana X., Kekana M. Protests continue at CPUT and Fort Hare, tensions flare. URL: http:// ewn.co.za/2015/10/20/tensions-flare-at-CPUT-andFort-Hare-fee-protest.

10. Language Policy (2016-2017). URL: http:// www.sun.ac.za/english/about-us/language.

11. Lazar S. "Fees must fall": student uprising for justice sweeps South Africa. URL: http://commondreams. org/news/2015/10/22/fees-must-fall-student-uprisingjustice-sweeps-south-africa.

12. Merten M. Riot police vs student power. URL: http://www.iol.co.za/news/crime-courts/riot-police-vsstudent-power-1933836.

13. Nicolson G. Fess must fall: Reloaded. URL: http://dailymaverick.co.za/article/2016-01-12-feesmust-fall-reloaded.

14. Nicolson G. Fees Must Fall: Convention brawling highlights. URL: http://dailymaverick.co.za/ article/2017-03-20-fees-must-fall.

15. Rensburg A.J. van. Disappointment after chaotic education convention cancelled. URL: http:// www.news24.com/South Africa/News/disappointmentafter-chaotic-education-convention-cancelled20170318.

16. South African Students continue fees protest. URL: http://bbc.com/news/world-africa34636419.

17. Student are not impressed by Blade's fee Adjustment Announcement. URL: http://www. thedailyvox.co.za/studant-across-country-respondedblades-fee-annoncement.

18. Verasamy D. What you need to know about \#FeesMustFall. URL: http://mg.co.za/article/2015-1019 -four-things-you-need-to-known-aboutfeesmustfall.

\section{Information about the Author}

Valentina V. Gribanova, Candidate of Sciences (History), Senior Researcher, Centre for History and Cultural Anthropology, Institute for African Studies of Russian Academy of Sciences, Spiridonovka St., 30/1, 123001 Moscow, Russian Federation, vgribanova@mail.ru, https://orcid.org/0000-0002-4117-1995

\section{Информация об авторе}

Валентина Валерьевна Грибанова, кандидат исторических наук, старший научный сотрудник Центра истории и культурной антропологии, Институт Африки РАН, ул. Спиридоновка, 30/1, 123001 г. Москва, Российская Федерация, vgribanova@mail.ru, https://orcid.org/0000-0002-4117-1995 